40-1| 2015

Enjeux contemporains en études irlandaises - In

Memoriam Paul Brennan

\title{
Claire Bracken et Emma Radley, Viewpoints, Theoretical Perspectives on Irish Visual Texts
}

\section{Valérie Morisson}

\section{(2) OpenEdition}

Journals

Édition électronique

URL : http://journals.openedition.org/etudesirlandaises/4685

DOI : 10.4000/etudesirlandaises.4685

ISSN : 2259-8863

Éditeur

Presses universitaires de Rennes

Édition imprimée

Date de publication : 30 juin 2015

Pagination : 375-378

ISBN : 978-2-7535-4082-8

ISSN : 0183-973X

Référence électronique

Valérie Morisson, «Claire Bracken et Emma Radley, Viewpoints, Theoretical Perspectives on Irish Visual Texts », Études irlandaises [En ligne], 40-1 | 2015, mis en ligne le 30 juin 2015, consulté le 05 mai 2019 URL : http://journals.openedition.org/etudesirlandaises/4685

Ce document a été généré automatiquement le 5 mai 2019.

(c) Presses universitaires de Rennes 


\title{
Claire Bracken et Emma Radley, Viewpoints, Theoretical Perspectives on Irish Visual Texts
}

\author{
Valérie Morisson
}

\section{RÉFÉRENCE}

Claire Bracken et Emma Radley, Viewpoints, Theoretical Perspectives on Irish Visual Texts, Cork, Cork University Press, 2013, 278 p, ISBN 978-1-85918-496-7.

1 Claire Bracken, spécialiste de la culture irlandaise et du post-féminisme, et Emma Radley, spécialiste de cinéma irlandais, codirigent cet ouvrage collectif proposant des analyses interdisciplinaires de la culture visuelle irlandaise contemporaine. L'ouvrage, dans son ensemble, démontre que les productions visuelles interprètent la société irlandaise contemporaine et son histoire de manières diverses et problématiques, participant ainsi à la réévaluation de l'inscription de ces productions et de leur réception critique dans une culture nationale. Les 14 articles du volume mettent en exergue les cadres idéologiques et critiques qui sous-tendent la manière dont l'Irlande s'imagine ou se donne à voir sans avoir recours à des représentations iconiques persistantes rendues caduques dans l'Irlande du xxI siècle. L'ouvrage s'inscrit dans une série de travaux récents proposant une approche holistique des représentations culturelles et interrogeant les théories et paradigmes qui, depuis les approches développées dans cadre du Field Day Project, ont permis de penser la culture irlandaise. L'image de l'Irlande véhiculée par les productions visuelles est sans cesse refaçonnée puisqu'elle qu'elle résulte de traditions revisitées et réactivées mais aussi d'interactions multidirectionnelles entre passé, présent et futur. Il s'agit, à travers un ensemble d'essais réunis dans trois sections interdisciplinaires et programmatiques (Discourse, Form, Identity) de relire des productions littéraires, cinématographiques, télévisuelles, photographiques, ou publicitaires en convoquant des approches non-spécifiquement irlandaises: perspectives féministes, psychanalytiques, 
phénoménologiques ou philosophiques. La lecture de Viewpoints permet à nouveau que soit posée la question de la spécificité nationale des productions visuelles : existe-t-il un cinéma irlandais? Comment les photographes, réalisateurs, écrivains irlandais déjouent les pièges de l'adaptation de canons internationaux à des réalités sociales, politiques, économiques ou culturelles irlandaises pour créer un espace de réflexion ouvert et dialogique?

2 Comme le souligne Justin Carville dans «Terra Infirma: The Territory of the Visible and the Writing of Ireland's Visual Culture ", si les analyses des créations visuelles se sont multipliées, la place de la culture visuelle au sein des productions culturelles reste difficile à définir en raison de leur complexité et de leur diversité. Les approches théoriques sont multiples, empruntant à l'histoire de l'art, à l'historiographie ou aux études postcoloniales. Dans son étude d'un portrait photographique ayant appartenu à l'anthropologue Alfred Cort Haddon, Carville propose une approche matérialiste de l'œuvre centrée sur les pratiques culturelles et visuelles régissant la production et la réception de la photographie en Irlande. Il sonde la perméabilité des frontières culturelles et artistiques pour conclure à l'ouverture de l'image photographique qui fait entendre plusieurs voix ou qui condense plusieurs regards.

3 Les nombreux articles portant sur des films irlandais ou nord-irlandais offrent une relecture de ces derniers à la lumière soit d'une phénoménologie des pratiques sociales dérivée de la notion bourdieusienne d'habitus (Cheryl Herr, « World-Making in Thaddeus O'Sullivan's The Woman Who Married Clark Gable»), soit d'une approche axée sur la relation entre le spectateur et le projet narratif du cinéaste, conscient de créer du sens, c'est-à-dire sur une intentionnalité phénoménologique (Barry Monahan, «The Phenomenological narrative shift between Lenny Abrahamson's Adam and Paul and Garage »), soit d'une approche politique du visuel et de la fascination qu'il exerce par la monstration de la violence dans des dispositifs marqués par les discours sur la question nord-irlandaise (Matthew Brown, « Fascinating States : Screening Northern Ireland »).

Plusieurs articles montrent à quel point les identités genrées sont déconstruites dans la culture visuelle contemporaine. Dans "Post-Feminism and the Celtic Tiger", Claire Bracken fait une lecture des séries télévisuelles Paths to Freedom et Fergus's Wedding (2000 et 2002) qui replace la critique post-féministe dans les champs politiques et économiques. L'auteur croise plusieurs grilles d'analyse en empruntant aux études de genre et, plus précisément aux théories de Luce Irigaray, aux queer studies, mais aussi aux critiques du capitalisme, sondant par ce biais les incarnations problématiques de l'homo economicus. Jenny O'Connor relit les films de Neil Jordan en convoquant la notion de «devenirfemme » proposée par Deleuze et Guattari : figure interstitielle, la femme s'hybride et remet en cause la binarité des constructions genrées. «Mourning Sex », de Fintan Walsh pose la question de savoir si le cinéma irlandais donne à voir la sexualité par un prisme national. Il réexamine Adam \& Paul et Garage à l'aune des arguments développés par Patricia MacCormack (Cinesexuality, 2008) pour conclure qu'une brèche esthétique a été ouverte dans un imaginaire qui n'accepte que difficilement que les genres sexués soient confondus.

5 L'ouvrage réunit plusieurs articles démontrant que les productions visuelles contribuent à enrichir la compréhension de l'identité nationale parce qu'elles en offrent des descriptions complexes. Heather Macdougall se penche sur les productions télévisuelles bilingues ou sous-titrées ; Emmie McFadden avance que Liam de Stephen Frears comprend des références intertextuelles variées à même de compliquer la lecture de la diaspora et 
de brouiller la notion d'origine; Emma Radley étudie la superposition d'une sémiotique de genre et de représentations nationales dans un article centré sur le film d'horreur et empruntant aux théories de Julia Kristeva. Ce sont également deux films d'horreur ( Isolation et Boy Eats Girl) que Zélie Asava analyse en interrogeant la manière dont les personnages, parfois d'origine étrangère, symbolisent l'identité nationale ou bien une hybridité qui la menace. C'est une identité fragmentée que Colin Graham met en avant dans l'analyse, inspirée de Théodore Adorno, qu'il fait de trois portraits photographiques réalisés par Joe Duggan, Hannah Starkey et John Gerrard. Graham conclue que si ces portraits peuvent être lus comme étant ceux d'irlandais, le clivage de l'individu dans ces images post-historiques et l'illusion du soi sont cosmopolites.

6 Viewpoints scrute également une culture plus populaire. Ainsi, Anne Mulhall propose une analyse des stratégies marketing de l'industrie du bien-être et des lieux de spiritualité en Irlande (Lough Derg et Krishna Island) qui fait dialoguer marchandisation capitaliste de la spiritualité bouddhiste et authenticité rurale prémoderne.

7 On retiendra des différents articles composant l'ouvrage que les productions visuelles n'ont de cesse de déconstruire les stéréotypes identitaires pour ouvrir des espaces de réflexion où différentes lectures, différents points de vue, différentes philosophies coexistent. De nouveaux discours et cadres théoriques offrant une alternative aux lectures nationales de la culture viennent compliquer le sens des productions visuelles. Plurielles et équivoques, ces dernières s'avèrent être des espaces représentationnels et critiques de négociations.

\section{AUTEURS}

\section{VALÉRIE MORISSON}

Université de Bourgogne 